Article

\title{
Thermochemical Measurements of Alkali Cation Association to Hexatantalate
}

\author{
Dylan J. Sures ${ }^{1,2, *(\mathbb{D}, \text { G. P. Nagabhushana }}{ }^{3} \mathbb{D}$, Alexandra Navrotsky ${ }^{3} \mathbb{D}$ and May Nyman ${ }^{1, *(\mathbb{D})}$ \\ 1 Department of Chemistry, Oregon State University, Corvallis, OR 97331-4003, USA \\ 2 Department of Chemistry, University of California, Davis, One Shields Avenue, Davis, CA 95616, USA \\ 3 Peter A. Rock Thermochemistry Laboratory and NEAT ORU, University of California Davis, \\ Davis, CA 95616, USA; gpnbhushan@gmail.com (G.P.N.); anavrotsky@ucdavis.edu (A.N.) \\ * Correspondence: sures@ucdavis.edu (D.J.S.); may.nyman@oregonstate.edu (M.N.)
}

Academic Editor: Santiago Reinoso

Received: 6 September 2018; Accepted: 19 September 2018; Published: 24 September 2018

check for updates

\begin{abstract}
Ion association is an important process in aqueous dissolution, precipitation, and crystallization of ionic inorganic, organic, and biological materials. Polyoxometalates (POMs) are good model compounds for understanding the complex relationships between lattice energy, ion-pairing in solution, and salt solubility. Here we perform calorimetric measurements to elucidate trends in cluster stability, lattice energy, and ion-pairing behavior studies of simple hexatantalate salts in neat water, parent hydroxide solutions, and molybdate melts, extending previous studies on the isostructural hexaniobates. High temperature calorimetry of alkali salts of hexatantalate reveals that the enthalpies of formation from oxides of the $\mathrm{K}, \mathrm{Rb}$, and $\mathrm{Cs}$ salts are more similar to each other than they are for their niobate analogues and that the tantalate cluster is energetically less stable than hexaniobate. Aqueous dissolution calorimetry reveals that the cesium salt of hexatantalate has a similar concentration dependence on its dissolution enthalpy to that of hexaniobate. However, unlike rubidium hexaniobate, rubidium hexatantalate also exhibits increased concentration dependence, indicating that hextantalate can undergo increased ion-pairing with alkali salts other than cesium, despite the dilute environments studied. Dissolution enthalpies of POM salts in the parent alkali hydroxides shows that protonation of clusters stabilizes lattices even more than the strongly associating heavy alkali cations do. Additionally, neither weak nor strong lattice ion associations necessarily correlates with respectively high or low aqueous solubility. These studies illuminate the importance of considering ion-pairing among the interrelated processes in the aqueous dissolution of ionic salts that can be extended to serving as a model of cation association to metal oxide surfaces.
\end{abstract}

Keywords: polyoxometalates; hexatantalate; tantalum; countercations; ion-pairing; calorimetry; solubility

\section{Introduction}

Aqueous ion behavior is driven by many fundamental and interrelated physical processes. The solubility of ionic salts in water is predictable to some degree by the "hardness" or "softness" of the component cations and anions, which arises from their degrees of hydration upon dissolution, electron count in the frontier molecular orbitals, overall charge, and charge density [1-4]. Typically, close interactions between cations and anions (ion-pairing) in solutions predicates precipitation, with larger hydration spheres from more charge-dense species (i.e., $\mathrm{Li}^{+}$) maintaining solubility, according to the Hoffmeister series [5]. This factor competes with lattice energy, which is a sum of energies of all the bonds present in the lattice. For simple monoatomic ions such as alkali halides, similarly sized cations and anions stabilize each other to the greatest degree, decreasing solubility. The relationship between lattice energy and solubility is less well defined for alkali salts of oxoanions; 
in particular, the anomalous solubilities of some highly charged oxoanions including carbonate [6,7], which is further complicated by protonation in solution.

We define anomalous solubility as increased solubility with increased ion-pairing, while normal solubility is the opposite. As an initial approximation, oxoanions and POMs with low charge density exhibit the typical solubility trend (less soluble with increasing alkali countercation size), whereas those with high charge densities exhibit the reversed, atypical solubility trend. Some common POMs and simple oxoanions, their charge densities (described here as cluster charge divided by number of cluster atoms), and observed solubility trends as alkali salts are summarized in Table 1 and below we provide a qualitative explanation of these opposite solubility trends. We surmise that oxo species with higher charge densities exhibit this atypical trend due to their ability to disrupt the relatively weakly bound hydration spheres of larger alkali cations (i.e., $\mathrm{Rb}^{+}$and $\mathrm{Cs}^{+}$), allowing for contact ion pairing. Because of the high POM/oxoanion charge, the alkali is strongly associated and therefore does not bridge to other oxoanions, suppressing aggregation and precipitation [8]. On the other hand, the high charge density of the same POMs/oxoanions does not completely satisfy bonding of the smaller and more charge-dense alkali cations (i.e., $\mathrm{Li}^{+}$and $\mathrm{Na}^{+}$), therefore these alkalis bridge $\mathrm{POM} /$ oxoanions in solution, initiating precipitation. Considering the low-charge density POMs, they may also form contact ion-pairs with larger alkalis, but these alkalis are not as strongly associated to a single POM/oxoanion. Rather they bridged two or more of these anions in solution, initiating precipitation. Finally the low-charge density POMs likely cannot penetrate the large hydration sphere of the charge-dense alkalis $\left(\mathrm{Li}^{+}, \mathrm{Na}^{+}\right)$, so there is no interaction in solution and solubility is retained.

Understanding the governing principles of solubility is important because it yields more complete models for thermodynamic calculations of aqueous speciation and ion association. Additionally, the solubility and association of ions in water affects their adsorption onto metal oxide surfaces [9], and knowledge of ion association can be used to fine-tune the electronic properties and chemical reactivities of catalysts, as well as design ion-specific sorbents [10-12].

Table 1. Charge densities, defined as the total charge divided by the number of non-hydrogen atoms, and solubility trends with respect to alkali countercations of several prominent oxoanions and POMs.

\begin{tabular}{cccc}
\hline Species & \# of Non-Hydrogen Atoms & Charge Density & Solubility Trend \\
\hline$\left[\mathrm{PO}_{4}\right]^{3-}$ & 5 & 0.6 & Anomalous [13] \\
{$\left[\mathrm{CO}_{3}\right]^{2-}$} & 4 & 0.5 & Anomalous [13] \\
{$\left[\mathrm{ClO}_{4}\right]^{-}$} & 5 & 0.2 & Normal [14] \\
\hline$\left[\mathrm{Nb}_{6} \mathrm{O}_{19}\right]^{8-}$ & 25 & 0.32 & Anomalous [15] \\
{$\left[\mathrm{Ta}_{6} \mathrm{O}_{19}\right]^{8-}$} & 25 & 0.32 & Anomalous [16] \\
{$\left[\mathrm{SiNb}_{12} \mathrm{O}_{40}\right]^{16-}$} & 53 & 0.30 & Anomalous [16] \\
{$\left[\mathrm{GaNb}_{18} \mathrm{O}_{54}\right]^{15-}$} & 73 & 0.21 & Anomalous [17] \\
\hline$\left[\mathrm{Nb}_{4} \mathrm{~W}_{2} \mathrm{O}_{19}\right]^{6-}$ & 25 & 0.24 & Anomalous [18] \\
{$\left[\mathrm{Nb}_{2} \mathrm{~W}_{4} \mathrm{O}_{19}\right]^{4-}$} & 25 & 0.16 & Normal [18] \\
\hline$\left[\mathrm{W}_{6} \mathrm{O}_{19}\right]^{2-}$ & 25 & 0.08 & Normal * \\
{$\left[\mathrm{SiW}_{12} \mathrm{O}_{40}\right]^{4-}$} & 53 & 0.075 & Normal [19] \\
{$\left[\mathrm{P}_{2} \mathrm{~W}_{18} \mathrm{O}_{62}\right]^{6-}$} & 82 & 0.073 & Normal [20] \\
{$\left[\mathrm{PW}_{12} \mathrm{O}_{40}\right]^{3-}$} & 53 & 0.057 & Normal [19] \\
\hline & ${ }^{*}$ Only soluble in organic solvents [21]. &
\end{tabular}

Polyoxometalates (POMs), nanoscale molecular oxoanions of Group V and VI metals in their highest oxidation states, can generally be synthesized with any alkali cation, thus providing an excellent model for ion-pairing in water and at metal oxide surfaces [15,22]. These "molecular metal oxides" exhibit a wide range of aqueous behaviors that depend on their metal centers and, crucially, their countercations [23]. The isostructural and isovalent hexaniobate $\left(\left[\mathrm{Nb}_{6} \mathrm{O}_{19}\right]^{8-}, \mathrm{Nb}_{6}\right)$ and hexatantalate $\left(\left[\mathrm{Ta}_{6} \mathrm{O}_{19}\right]^{8-}, \mathrm{Ta}_{6}\right)$ POMs exhibit very similar $\mathrm{pH}$ stabilities, and aqueous solubilities 
with respect to alkali countercations $[16,24,25]$. In particular, $\mathrm{Cs}^{+}$undergoes significant ion-pairing with these POMs, which increases their solubilities due to each $\mathrm{Cs}^{+}$more favorably interacting with a single cluster rather than coordinating to multiple clusters, wherein binding to a single cluster inhibits aggregation and precipitation, even at high concentration [8]. However, subtle differences have been found in their degrees of ion association with $\mathrm{Cs}^{+}$. For example, $\mathrm{Ta}_{6}$ undergoes greater ion-pairing than $\mathrm{Nb}_{6}$ with $\mathrm{Cs}^{+}$in dilute solutions in neat water, even at low concentration. This was attributed to the presence of relativistic effects in $\mathrm{Ta}_{6}$, which results in the orbital interaction term having a larger contribution to the total bonding energy [8]. In other words, electrostatics alone are insufficient to describe cation association in the presence of Group V POMs, and covalent bonding between the alkalis and oxo ligands may also be considered, in order to arrive at a complete description of solution behavior.

\section{Results \& Discussion}

\subsection{Solid-State Calorimetry of $\mathrm{Ta}_{6}$ Salts}

We previously conducted high-temperature oxide decomposition calorimetric studies on alkali $\left(\mathrm{Li}^{+}, \mathrm{K}^{+}, \mathrm{Rb}^{+}, \mathrm{Cs}^{+}\right)$salts of $\mathrm{Nb}_{6}$ [26]. Upon dropping pellets made from crystalline samples into molten sodium molybdate at $700^{\circ} \mathrm{C}$, we ascertained a trend of increasingly exothermic enthalpy of formation from oxides $\left(\Delta H_{f}^{o x}\right)$ with respect to alkali countercation size. To parallel this previous study, we performed measurements on the same alkali salts of $\mathrm{Ta}_{6}$. Although the $\mathrm{Na}_{8}\left[\mathrm{Ta}_{6} \mathrm{O}_{19}\right]$ salt can be synthesized, it was not studied because the analogous $\mathrm{Nb}_{6}$ salt is not readily obtained. Rather, $\mathrm{Na}_{7}\left[\mathrm{HNb}_{6} \mathrm{O}_{19}\right]$ is the common form [27]. The measured $\Delta H_{f}^{o x}$ is less exothermic for each alkali $\mathrm{Ta}_{6}$ analogue, compared to the $\mathrm{Nb}_{6}$ analogue (Figure 1). We rationalize this as mixing of $\mathrm{Ta}_{5 d}$ and $\mathrm{O}_{2 p}$ orbitals in $\mathrm{Ta}_{6}$ being poorer than the mixing between $\mathrm{Nb}_{4 d}$ and $\mathrm{O}_{2 p}$ in $\mathrm{Nb}_{6}$ [8,18], decreasing the thermodynamic stability of the $\mathrm{Ta}_{6}$ cluster in comparison to the $\mathrm{Nb}_{6}$ cluster. As with the observed trend for hexaniobate, the $\mathrm{Li}^{+}$salt of $\mathrm{Ta}_{6}$ exhibits a far less exothermic (by more than a factor of two) $\Delta H_{f}^{o x}$ than the larger alkali salts. This is explained by the structure of lithium hexaniobate [28,29]. The hexaniobate lattice contains adamantane-like Li-water clusters, which prevents extensive direct bonding between $\mathrm{Li}^{+}$and $\mathrm{Nb}_{6}$. A high-resolution single-crystal structure of $\mathrm{Li}-\mathrm{Ta}_{6}$ has never been possible, due to poor crystal quality and perhaps disorder of the hydrated lithium in the lattice. We surmise that $\mathrm{Li}-\mathrm{Ta}_{6}$ is not isostructural with the $\mathrm{Li}-\mathrm{Nb}_{6}$ analogue $\left(\mathrm{Li}_{8} \mathrm{Nb}_{6} \mathrm{O}_{19} \cdot 22 \mathrm{H}_{2} \mathrm{O}\right)$ due to the lack of a reported single-crystal structure for lithium hexatantalate [30,31]. However, Li is generally bonded to water in hydrated salt lattices, and this is reflected in its less exothermic formation enthalpy, compared to the salts of the heavier alkalis. Unlike $\mathrm{Nb}_{6}$, the $\mathrm{K}^{+}, \mathrm{Rb}^{+}$, and $\mathrm{Cs}^{+}$salts of $\mathrm{Ta}_{6}$ do not exhibit a strict trend of increasing $\Delta H_{f}^{o x}$ (Figure 1). Instead, the three larger alkali salts are more similar in their $\Delta H_{f}^{o x}$. This suggests that Ta ${ }_{6}$ is slightly 'less selective' in its solid-state ion association than $\mathrm{Nb}_{6}$.

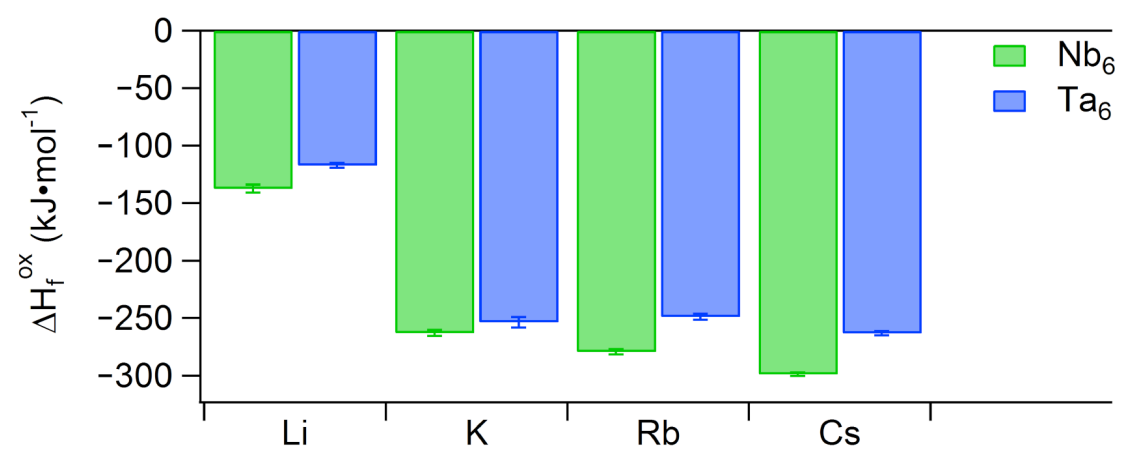

Figure 1. Solid-state $\Delta H_{f}^{o x}$ (enthalpy of formation from oxides, $\mathrm{kJ}(\mathrm{mol}-\mathrm{Nb})^{-1}$ ) values for alkali salts of $\mathrm{Ta}_{6}$ (this study) and $\mathrm{Nb}_{6}$ (prior study) [26]. 


\subsection{Dissolution Energy of $\mathrm{Ta}_{6}$ Salts}

While high-temperature calorimetry provides information about the stability of the clusters and their association with lattice species, solution calorimetry elucidates hydration enthalpies of the ions upon dissolution, as well as their solid-state lattice interactions. Enthalpy of dissolution $\left(\Delta H_{d i s}\right)$ at room temperature of the $\mathrm{Nb}_{6}$ salts in neat water showed that the Cs-salt has greater concentration dependence in its dissolution enthalpy compared to the other alkali salts. By extension, the degree of structural change became less extensive at higher concentrations, indicating that the $\mathrm{Cs}^{+}$underwent maximum ion-pairing with $\mathrm{Nb}_{6}$, even at the low concentrations $(<2 \mathrm{mM})$. Analogous measurements of $\mathrm{Ta}_{6}$ salts also showed $\Delta H_{\text {dis }}$ concentration dependence for each alkali salt (Figure 2). $\mathrm{Li}^{+}$again cannot be easily compared to the larger alkalis, due to its far more extensive coordination to water molecules in the solid state. This is reflected in its overall lower values of $\Delta H_{d i s}$ compared to the other three alkali salts, meaning it is not necessary to disrupt extensive bonding between the clusters and alkalis to dissolve them, which is an endothermic process. However, the steeper slope of the Cs- $\mathrm{Ta}_{6}$ trend was matched by the $\mathrm{Rb}^{+}$salt, with $\mathrm{K}^{+}$having a smaller slope. This indicates that rubidium and cesium undergo similar degrees of ion-pairing with $\mathrm{Ta}_{6}$ in solution, which is different from the observed $\mathrm{Nb}_{6}$ trend, in which the cesium salt clearly had the greatest dependence on concentration. Like the high-temperature calorimetry, this too indicates that $\mathrm{Ta}_{6}$ is 'less selective' in its ion association than $\mathrm{Nb}_{6}$ (in both solution and solid state). On the other hand, it has been noted that $\mathrm{Nb}_{6}$ is more basic than $\mathrm{Ta}_{6}$, meaning it protonates upon dissolution in water, at the bridging oxos sites [32,33]. Since protonation is an endothermic process that is not equal between the $\mathrm{Ta}_{6}$ and $\mathrm{Nb}_{6}$, it is difficult to compare the dissolution enthalpy with exact certainty.

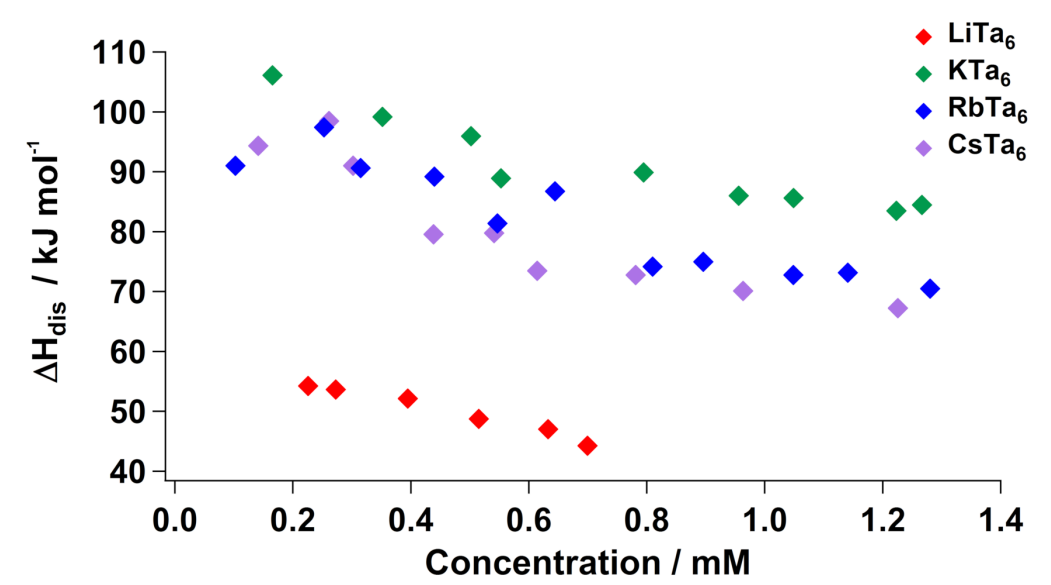

Figure 2. Enthalpy of aqueous dissolution $\left(\Delta H_{d i s}\right)$ of $\mathrm{Li}-\mathrm{Ta}_{6}, \mathrm{~K}-\mathrm{Ta}_{6}, \mathrm{Rb}-\mathrm{Ta}_{6}$ and $\mathrm{Cs}-\mathrm{Ta}_{6}$ in water, normalized for lattice water (i.e., representing dissolution of the dehydrated forms $\mathrm{Li}_{8}\left[\mathrm{Ta}_{6} \mathrm{O}_{19}\right]$, $\mathrm{K}_{8}\left[\mathrm{Ta}_{6} \mathrm{O}_{19}\right], \mathrm{Rb}_{8}\left[\mathrm{Ta}_{6} \mathrm{O}_{19}\right]$ and $\mathrm{Cs}_{8}\left[\mathrm{Ta}_{6} \mathrm{O}_{19}\right]$; the hydrated enthalpies are provided in Tables S5-S9).

We dissolved the $\mathrm{K}, \mathrm{Rb}$ and $\mathrm{Cs} \mathrm{Ta}_{6}$ salts in 1 molar solutions of each alkali cation's parent hydroxide (Figure 3). The $\mathrm{Li}^{+}$salt was omitted due to its insolubility in $\mathrm{LiOH}$. Like $\mathrm{Nb}_{6}$, alkali salts of $\mathrm{Ta}_{6}$ do not have a concentration dependence when dissolved in base, due to a lack of cluster protonation and the excess cations in solution forcing the "maximally associated" state at all concentrations. The generally more exothermic dissolution enthalpies can be related to the lack of protonation of the clusters with high concentration of base. There is a distinct trend in $\Delta H_{d i s}$ with respect to alkali cation size; with Cs- $\mathrm{Ta}_{6}$ being most exothermic, followed by $\mathrm{Rb}-\mathrm{Ta}_{6}$ and then $\mathrm{K}-\mathrm{Ta}_{6}$. This trend suggested that less energy is required to dissociate the $\mathrm{Cs}-\mathrm{Ta}_{6}$ lattice adequately to achieve dissolution, compared to the $\mathrm{K}$ and $\mathrm{Rb}$ analogues. This is exactly consistent with ion-pairing persisting in solution: increasing $\mathrm{K}-\mathrm{Ta}_{6}<$ $\mathrm{Rb}-\mathrm{Ta}_{6}<\mathrm{Cs}-\mathrm{Ta}_{6}$. The solutions remain monodisperse and no appreciable amount of impurities form with added solid $\mathrm{Ta}_{6}$, accounted for by previous small-angle $\mathrm{X}$-ray scattering studies of hexatantalate in 1 molar parent hydroxide solution [24]. We also do not expect any impurities or cluster alteration 
upon dissolution in hydroxide solutions because the hexatantalate form is most stable in conditions of high concentration hydroxide, confirming that the flatlining of $\Delta H_{\text {dis }}$ is strictly from maximal $\mathrm{A}-\mathrm{Ta}_{6}$ ion-pairing.

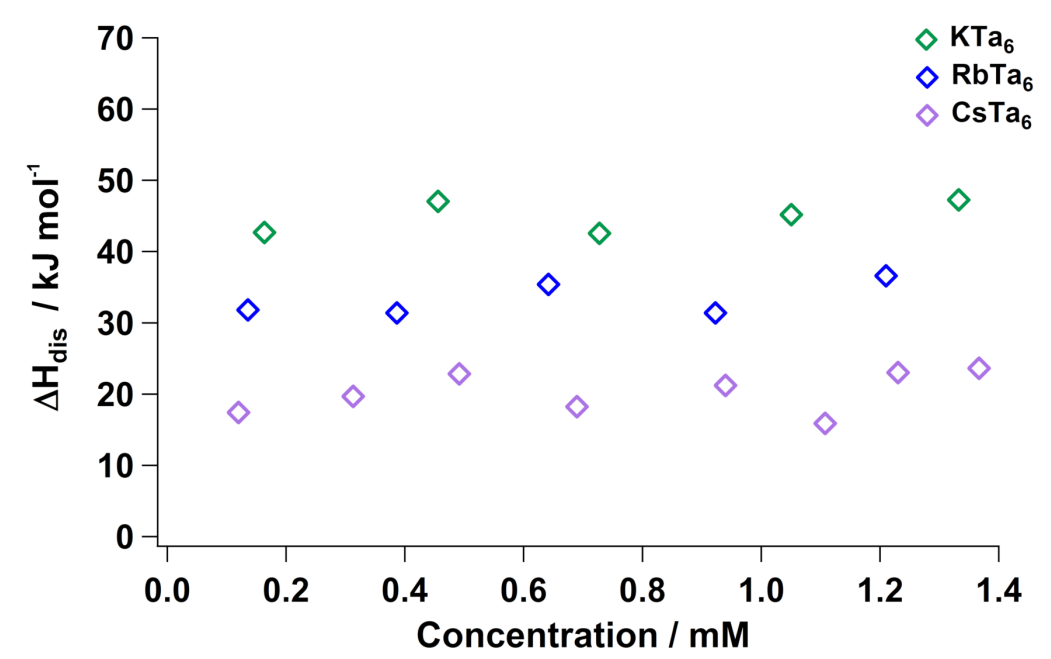

Figure 3. Enthalpy of aqueous dissolution $\left(\Delta H_{d i s}\right)$ of $\mathrm{Li}-\mathrm{Ta}_{6}, \mathrm{~K}-\mathrm{Ta}_{6}, \mathrm{Rb}-\mathrm{Ta}_{6}$ and $\mathrm{Cs}-\mathrm{Ta}_{6}$ in their parent hydroxide $(1 \mathrm{M})$ solutions, normalized for lattice water. The hydrated enthalpies are provided in Tables S10-S13.

Finally, we compared the $\Delta H_{\text {dis }}$ of the tetramethylammonium salt of $\mathrm{Ta}_{6}\left(\left[\left(\mathrm{CH}_{3}\right)_{4} \mathrm{~N}_{6} \mathrm{H}_{2} \mathrm{O}_{19} \cdot 21 \mathrm{H}_{2} \mathrm{O}\right.\right.$, TMA-Ta ${ }_{6}$ ) in water and in 1 molar TMAOH to the previously measured $\mathrm{Nb}$ analogue (Figure 4 ). As with the analogous $\mathrm{TMA}-\mathrm{Nb}_{6}$ study, $\Delta H_{\text {dis }}$ does not have a concentration dependence in either solution environment due to the lack of ion association between $\mathrm{TMA}^{+}$and $\mathrm{Ta}_{6}$. However, $\Delta H_{\text {dis }}$ is less exothermic for TMA-Ta $\left(\sim-10 \mathrm{~kJ} \mathrm{~mol}^{-1}\right)$ than it is for TMA-Nb $\left(\sim-40 \mathrm{~kJ} \mathrm{~mol}^{-1}\right)$ in water. As described above, this is because $\mathrm{Ta}_{6}$ is a weaker base than $\mathrm{Nb}_{6}$ [25], resulting in a lesser degree of deprotonation, consistent with fewer exothermic events occurring in solution. The difference in $\Delta H_{\text {dis }}$ between TMA-Ta 6 and TMA-Nb ${ }_{6}$ is greatly enhanced in $1 \mathrm{M} \mathrm{TMAOH}\left(\sim-35 \mathrm{~kJ} \mathrm{~mol}^{-1}\right.$ and $\left(\sim-35 \mathrm{~kJ} \mathrm{~mol}^{-1}\right.$, respectively). This is due to the tendency for $\mathrm{TMA}^{-\mathrm{Nb}_{6}}$ to form oligomeric chains in neat water, whereas $\mathrm{TMA}-\mathrm{Ta}_{6}$ typically forms dimers [24]. Thus, the vast difference in exothermic dissolution is further explained by the degree of hydrolysis of the respective assemblies - a far greater number of exothermic events occur in dissociating the $\mathrm{Nb}_{6}$ chains than in dissociating $\mathrm{Ta}_{6}$ dimers. The $\Delta H_{d i s}$ is nonetheless more exothermic for $\mathrm{TMA}-\mathrm{Ta}_{6}$ in $1 \mathrm{M}$ TMAOH than it is in neat water due to the disassembly of these dimers.

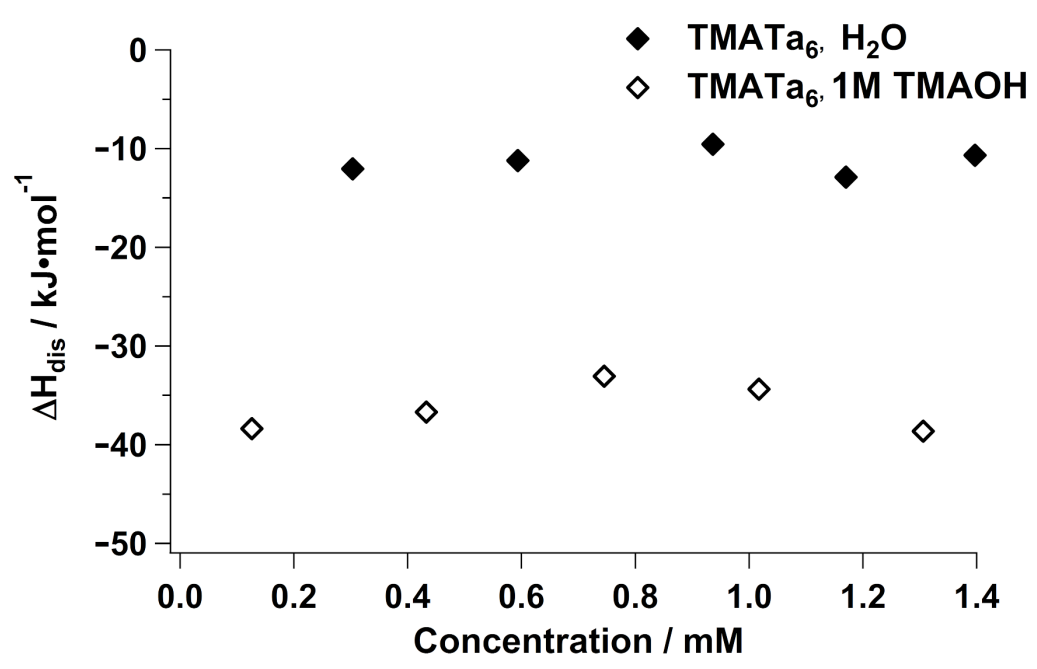

Figure 4. Enthalpy of dissolution of TMA-Ta ${ }_{6}$ in neat water and in $1 \mathrm{M} \mathrm{TMAOH}$. 


\section{Materials and Methods}

\subsection{Determination of Drop Solution Enthalpies}

$\Delta H_{d s}$ was measured in a custom-made isoperibol Tian-Calvet twin microcalorimeter. Pellets of about $5 \mathrm{mg}$ were loosely pressed, weighed, and dropped from room temperature into $3 \mathrm{Na}_{2} \mathrm{O} \cdot 4 \mathrm{MoO}_{3}$ molten solvent at $702^{\circ} \mathrm{C}$. The calorimeter assembly was washed with oxygen at $43 \mathrm{~mL} \mathrm{~min}^{-1}$. Oxygen was bubbled through the solvent at $4.5 \mathrm{~mL} \mathrm{~min}^{-1}$ to aid dissolution, evolve water vapor, and to maintain oxidizing conditions. The calorimeter was calibrated against the heat content of $5 \mathrm{mg}$ pellets of high-purity $\mathrm{Al}_{2} \mathrm{O}_{3}(99.997 \%$, Alfa Aesar) dropped into an empty crucible.

\subsection{Determination of Room Temperature Dissolution Enthalpies}

$\Delta H_{\text {dis }}$ was measured using a CSC 4400 isothermal microcalorimeter operated at $25^{\circ} \mathrm{C}$. About 10-25 mg of each sample was hand pressed into a pellet and dropped one at a time into $25.0 \mathrm{~g}$ of $\mathrm{H}_{2} \mathrm{O}$. Each experiment was repeated in $1 \mathrm{M} \mathrm{AOH}(\mathrm{A}=\mathrm{K}, \mathrm{Rb}, \mathrm{Cs}, \mathrm{TMA})$ for the respective clusters. The lithium salt was omitted due to its insolubility.

The calorimeter was calibrated by dissolving $15 \mathrm{mg}$ pellets of $\mathrm{KCl}$ in water with stirring at $25^{\circ} \mathrm{C}$. Hydrous and anhydrous cluster dissolution enthalpy values in water are reported in Tables S5-S9 and parent hydroxide values are reported in Tables S10-S13.

Enthalpies of anhydrous clusters were found by subtracting the enthalpy of dissolution of lattice water $\left(0.4 \mathrm{~kJ} \mathrm{~mol}^{-1}\right)$ [34] and then adjusting for the relative molar weights of the hydrated and anhydrous clusters, namely:

$$
\Delta H_{\text {dis, anhydrous }}=\left(\Delta H_{\text {dis,hydrated }}-\left(0.4 \mathrm{~kJ} \mathrm{~mol}^{-1}\right)\left(n_{\mathrm{H}_{2} \mathrm{O}}\right)\right) \frac{\mathrm{MW}(\text { Anhydrous Cluster })}{\mathrm{MW}(\text { Hydrated Cluster })}
$$

\subsection{Thermogravimetric Analysis}

Thermogravimetry was used to determine number of lattice waters per cluster. These experiments were performed on a Setaram LabSys Evo. The sample was heated in an alumina crucible from $25^{\circ} \mathrm{C}$ to $600{ }^{\circ} \mathrm{C}$ in an inert atmosphere at $10{ }^{\circ} \mathrm{C} \mathrm{min}^{-1}$. The total weight loss was determined at the temperature where weight \% reached a minimum (Figures S5-S8).

\subsection{Syntheses}

\subsubsection{Alkali Salts}

The larger alkali salts of $\left[\mathrm{Ta}_{6} \mathrm{O}_{19}\right]^{8-}$ were synthesized by refluxing a $\approx 40 \mathrm{mM}$ solution of their peroxotantalate analogues $\left(\mathrm{A}_{3} \mathrm{Ta}\left(\mathrm{O}_{2}\right)_{4} ; \mathrm{A}=\mathrm{K}, \mathrm{Rb}, \mathrm{Cs}\right)$ in concentrated parent alkali hydroxide solution for $4 \mathrm{~h}$, except for the lithium salt, which was formed by metathesis of the potassium salt in $1 \mathrm{M} \mathrm{LiOH}$ solution. The peroxotantalates were formed by adding $4.6 \mathrm{~g} \mathrm{TaCl} \mathrm{T}_{5}$ to $40 \mathrm{~mL}$ of cold $30 \%(w / w) \mathrm{H}_{2} \mathrm{O}_{2}$ solution, adding concentrated $\mathrm{AOH}$ solutions $(\mathrm{A}=\mathrm{K}, \mathrm{Rb}, \mathrm{Cs})$, and precipitating with ethanol. Full syntheses are described in a prior publication [27].

\subsubsection{Tetramethylammonium Salt}

Tetramethylammonium hexatanatalate $\left(\left[\left(\mathrm{CH}_{3}\right)_{4} \mathrm{~N}_{6} \mathrm{H}_{2} \mathrm{Ta}_{6} \mathrm{O}_{19}\right)\right.$ was synthesized by adding $1.32 \mathrm{~g}$ of $\left(\mathrm{NH}_{4}\right)_{3} \mathrm{Ta}\left(\mathrm{O}_{2}\right)_{4}$ to $8.25 \mathrm{~mL}$ of $1.4 \mathrm{M}$ tetramethylammonium hydroxide and refluxing for $5 \mathrm{~h}$. The solution was then microfiltered, $40 \mathrm{~mL}$ isopropyl alcohol was added, and then the resulting solution was centrifuged to yield a small denser layer containing the product. The supernatant was discarded and further addition of $30 \mathrm{~mL}$ isopropyl alcohol yielded a white precipitate, which was washed with more isopropyl alcohol and oven-dried under vacuum at $60{ }^{\circ} \mathrm{C}$ [24]. 


\section{Conclusions}

This study represents a rare quantitative evaluation of combined high temperature and aqueous dissociation energy of water-soluble metal-oxo clusters, elucidating the correlation between ion-association and acid-base behavior in dissolution of cluster salts, as well as the stability of the clusters. Experimentally determined enthalpy of formation of the $\mathrm{Nb}$ and $\mathrm{Ta}$ hexametalate POMs showed lower thermodynamic stability of the Ta-analogues compared to the $\mathrm{Nb}$-analogues, regardless of the alkali counterion. This is consistent with the slightly larger ionic radius of $\mathrm{Ta}^{5+}$ than $\mathrm{Nb}^{5+}$, and corresponding weaker $\mathrm{M}-\mathrm{O}$ bonds within the POM. While all cluster salts exhibit negative enthalpy of formation from oxides, there is a periodic trend of increasingly exothermic enthalpy with increasing alkali size. Notably fewer negative enthalpies are measured for the Li-salts compared to the heavier congeners, due to minimal cluster-cation association within the lattice (lower lattice energy). Aqueous dissolution enthalpy is the net sum of both endothermic and exothermic processes including protonation and/or deprotonation of the oxoanion POMs, dissociation of ions, and hydration of ions. With the various solutions (neat water and parent hydroxides) and various countercations (alkalis and tetramethylammounium, TMA) for the $\mathrm{Nb}$ and Ta hexametalates, we can conclude the following about cation-oxoanion lattice energetics. First, protonation of oxoanions such as POMs stabilize lattices even more than the strongly associated heavier alkali cations. Second, solubility of oxoanions cannot be described as inversely correlated with their lattice energy: we observed both the most negative and the most positive lattice energies for the two most soluble salts, respectively with $\mathrm{TMA}^{+}$and with $\mathrm{Cs}^{+}$ counterions. This means that lattice energy, as classically described by the Born-Haber cycle, does not necessarily predict solubility of oxoanion salts, or lattices containing aqua species.

Supplementary Materials: The following are available online. Thermochemical Cycles (with oxide drop solution enthalpies taken from previous studies) [35], values for hydrated (non-normalized for water) enthalpies of dissolution, thermogravimetric analyses, and energy dispersive X-ray spectra are available as Supplementary Information.

Author Contributions: Conceptualization, D.J.S., A.N. and M.N.; Formal analysis, D.J.S., G.P.N., A.N. and M.N.; Funding acquisition, A.N. and M.N.; Investigation, D.J.S., G.P.N., A.N. and M.N.; Methodology, D.J.S., G.P.N., A.N. and M.N.; Project administration, A.N. and M.N.; Resources, A.N. and M.N.; Supervision, G.P.N. and A.N.; Visualization, D.S., A.N. and M.N.; Writing—original draft, D.J.S.; Writing—review \& editing, D.J.S., G.P.N., A.N. and M.N.

Funding: The studies performed at OSU and UCD by DS and MN were supported by the U.S. Department of Energy, Office of Science, Basic Energy Sciences, under Award \# DE-SC0010802. GPN and AN acknowledge support by the U.S. Department of Energy, Office of Basic Energy Sciences, Division of Chemical and Geosciences, under award FG02-97ER14749.

Conflicts of Interest: The authors declare no conflict of interest.

\section{Abbreviations}

The following abbreviations are used in this manuscript:

$\begin{array}{ll}\mathrm{POM} & \text { Polyoxometalate } \\ \mathrm{Nb}_{6} & \text { Hexaniobate } \\ \mathrm{Ta}_{6} & \text { Hexatantalate } \\ \mathrm{TMA} & \text { Tetramethylammonium }\end{array}$

\section{References}

1. Pearson, R.G. Hard and soft acids and bases. J. Am. Chem. Soc. 1963, 85, 3533-3539. [CrossRef]

2. Ayers, P.W. An elementary derivation of the hard/soft-acid/base principle. J. Chem. Phys. 2005, 122, 141102. [CrossRef] [PubMed]

3. Li, Y.; Evans, J.N. The Fukui function: a key concept linking frontier molecular orbital theory and the hard-soft-acid-base principle. J. Am. Chem. Soc. 1995, 117, 7756-7759. [CrossRef]

4. Ayers, P.W.; Parr, R.G.; Pearson, R.G. Elucidating the hard/soft acid/base principle: A perspective based on half-reactions. J. Chem. Phys. 2006, 124, 194107. [CrossRef] [PubMed] 
5. Oncsik, T.; Trefalt, G.; Borkovec, M.; Szilagyi, I. Specific ion effects on particle aggregation induced by monovalent salts within the Hofmeister series. Langmuir 2015, 31, 3799-3807. [CrossRef] [PubMed]

6. Szwarc, M. Ions and Ion Pairs in Organic Reactions; John Wiley \& Sons: Hoboken, NJ, USA, 1974; Volume 2.

7. Linke, W.F. Solubilities, Inorganic and Metal Organic Compounds: A Compilation of Solubility Data from the Periodical Literature; Van Nostrand: Syracuse, NY, USA, 1965; Volume 2,

8. Sures, D.J.; Serapian, S.A.; Kozma, K.; Molina, P.I.; Bo, C.; Nyman, M. Electronic and relativistic contributions to ion-pairing in polyoxometalate model systems. Phys. Chem. Chem. Phys. 2017, 19, 8715-8725. [CrossRef] [PubMed]

9. Boehm, H. Acidic and basic properties of hydroxylated metal oxide surfaces. Discuss. Faraday Soc. 1971, 52, 264-275. [CrossRef]

10. Connor, G.P.; Holland, P.L. Coordination chemistry insights into the role of alkali metal promoters in dinitrogen reduction. Catal. Today 2017, 286, 21-40. [CrossRef] [PubMed]

11. Bonzel, H. Alkali-promoted gas adsorption and surface reactions on metals. J. Vac. Sci. Technol. A Vac. Surf. Films 1984, 2, 866-872. [CrossRef]

12. Mross, W. Alkali doping in heterogeneous catalysis. Catal. Rev. Sci. Eng. 1983, 25, 591-637. [CrossRef]

13. Seidell, A. Solubilities of Inorganic and Organic Compounds C. 2; D. Van Nostrand Company: New York, NY, USA, 1919.

14. Perry, D.L. Handbook of Inorganic Compounds; CRC Press: Boca Raton, FL, USA, 2016.

15. Nyman, M.; Alam, T.M.; Bonhomme, F.; Rodriguez, M.A.; Frazer, C.S.; Welk, M.E. Solid-state structures and solution behavior of alkali salts of the $\left[\mathrm{Nb}_{6} \mathrm{O}_{19}\right]^{8-}$ Lindqvist ion. J. Clust. Sci. 2006, 17, 197-219. [CrossRef]

16. Nyman, M. Polyoxoniobate chemistry in the 21st century. Dalton Trans. 2011, 40, 8049-8058. [CrossRef] [PubMed]

17. Hou, Y.; Nyman, M.; Rodriguez, M.A. Soluble heteropolyniobates from the bottom of group IA. Angew. Chem. Int. Ed. 2011, 50, 12514-12517. [CrossRef] [PubMed]

18. Sures, D.J.; Molina, P.I.; Miró, P.; Zakharov, L.N.; Nyman, M. Cesium salts of niobo-tungstate isopolyanions with intermediate group V-group VI character. New J. Chem. 2016, 40, 928-936. [CrossRef]

19. Krtil, J. Exchange properties of ammonium salts of 12-heteropolyacids-II: Separation of rubidium and caesium on ammonium phosphotungstate. J. Inorg. Nucl. Chem. 1961, 19, 298-303. [CrossRef]

20. Briand, L.E.; Baronetti, G.T.; Thomas, H.J. The state of the art on Wells-Dawson heteropoly-compounds: A review of their properties and applications. Appl. Catal. A Gen. 2003, 256, 37-50. [CrossRef]

21. Ginsberg, A.P. Inorganic Syntheses; John Wiley \& Sons: Hoboken, NJ, USA, 1990.

22. Fullmer, L.B.; Mansergh, R.H.; Zakharov, L.N.; Keszler, D.A.; Nyman, M. $\mathrm{Nb}_{2} \mathrm{O}_{5}$ and $\mathrm{Ta}_{2} \mathrm{O}_{5}$ thin films from polyoxometalate precursors: A single proton makes a difference. Cryst. Growth Des. 2015, 15, 3885-3892. [CrossRef]

23. Nyman, M.; Burns, P.C. A comprehensive comparison of transition-metal and actinyl polyoxometalates. Chem. Soc. Rev. 2012, 41, 7354-7367. [CrossRef] [PubMed]

24. Fullmer, L.B.; Molina, P.I.; Antonio, M.R.; Nyman, M. Contrasting ion-association behaviour of Ta and $\mathrm{Nb}$ polyoxometalates. Dalton Trans. 2014, 43, 15295-15299. [CrossRef] [PubMed]

25. Deblonde, G.J.P.; Moncomble, A.; Cote, G.; Bélair, S.; Chagnes, A. Experimental and computational exploration of the UV-visible properties of hexaniobate and hexatantalate ions. RSC Adv. 2015, 5, 7619-7627. [CrossRef]

26. Sures, D.J.; Sahu, S.K.; Molina, P.I.; Navrotsky, A.; Nyman, M. Distinctive interactions of cesium and hexaniobate in water. ChemistrySelect 2016, 1, 1858-1862. [CrossRef]

27. Anderson, T.M.; Rodriguez, M.A.; Bonhomme, F.; Bixler, J.N.; Alam, T.M.; Nyman, M. An aqueous route to $\left[\mathrm{Ta}_{6} \mathrm{O}_{19}\right]^{8-}$ and solid-state studies of isostructural niobium and tantalum oxide complexes. Dalton Trans. 2007, pp. 4517-4522. [CrossRef] [PubMed]

28. Anderson, T.M.; Thoma, S.G.; Bonhomme, F.; Rodriguez, M.A.; Park, H.; Parise, J.B.; Alam, T.M.; Larentzos, J.P.; Nyman, M. Lithium Polyniobates. A Lindqvist-supported lithium- water adamantane cluster and conversion of hexaniobate to a discrete Keggin complex. Cryst. Growth Des. 2007, 7, 719-723. [CrossRef] 
29. Hou, Y.; Fast, D.B.; Ruther, R.E.; Amador, J.M.; Fullmer, L.B.; Decker, S.R.; Zakharov, L.N.; Dolgos, M.R.; Nyman, M. The atomic level journey from aqueous polyoxometalate to metal oxide. J. Solid State Chem. 2015, 221, 418-425. [CrossRef]

30. Nyman, M.; Anderson, T.M.; Provencio, P.P. Comparison of aqueous and non-aqueous soft-chemical syntheses of lithium niobate and lithium tantalate powders. Cryst. Growth Des. 2008, 9, 1036-1040. [CrossRef]

31. Deblonde, G.J.P.; Coelho-Diogo, C.; Chagnes, A.; Cote, G.; Smith, M.E.; Hanna, J.V.; Iuga, D.; Bonhomme, C. Multinuclear solid-state NMR investigation of hexaniobate and hexatantalate compounds. Inorg. Chem. 2016, 55, 5946-5956. [CrossRef] [PubMed]

32. Matsumoto, M.; Ozawa, Y.; Yagasaki, A. Which is the most basic oxygen in $\left[\mathrm{Ta}_{6} \mathrm{O}_{19}\right]^{8-}$ ?-Synthesis and structural characterization of $\left[\mathrm{H}_{2} \mathrm{Ta}_{6} \mathrm{O}_{19}\right]^{6-}$. Inorg. Chem. Commun. 2011, 14, 115-117. [CrossRef]

33. Matsumoto, M.; Ozawa, Y.; Yagasaki, A. Long hydrogen-bonded rod of molecular oxide: A hexatantalate tetramer. Inorg. Chem. 2012, 51, 5991-5993. [CrossRef] [PubMed]

34. Robie, R.A.; Hemmingway, B.; Fisher, J.R. Thermodynamic Properties of Minerals and Related Substances at 298. $15 \mathrm{~K}$ and 1 Bar (10 Pascals) Pressure and at Higher Temperatures; U.S. Geological Survey: Reston, VA, USA, 1978.

35. Zlotnik, S.; Sahu, S.K.; Navrotsky, A.; Vilarinho, P.M. Pyrochlore and perovskite potassium tantalate: Enthalpies of formation and phase transformation. Chem. Eur. J. 2015, 21, 5231-5237. [CrossRef] [PubMed]

(C) 2018 by the authors. Licensee MDPI, Basel, Switzerland. This article is an open access article distributed under the terms and conditions of the Creative Commons Attribution (CC BY) license (http://creativecommons.org/licenses/by/4.0/). 